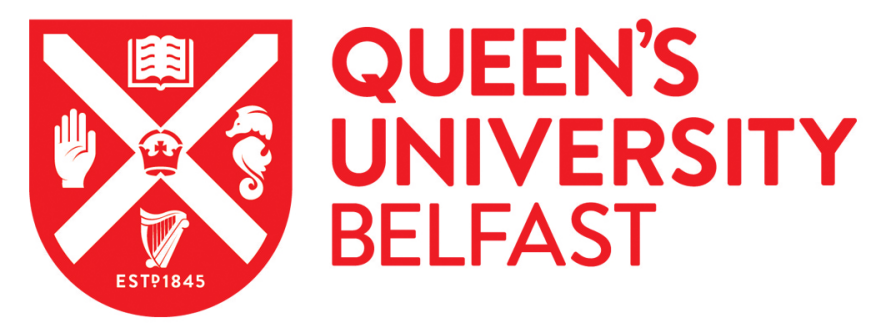

\title{
Ultra-Widefield Fluorescein Angiography as a Biomarker for Response to Switch in Therapy in Persistent DME
}

Bahrami, B., Hong, T., Peto, T., \& Chang, A. (2019). Ultra-Widefield Fluorescein Angiography as a Biomarker for Response to Switch in Therapy in Persistent DME. OSLIRetina, 50(12), 771-778.

https://doi.org/10.3928/23258160-20191119-04

\section{Published in:}

OSLIRetina

\section{Document Version:}

Peer reviewed version

Queen's University Belfast - Research Portal:

Link to publication record in Queen's University Belfast Research Portal

Publisher rights

Copyright 2019 Slack. This work is made available online in accordance with the publisher's policies. Please refer to any applicable terms of use of the publisher.

\section{General rights}

Copyright for the publications made accessible via the Queen's University Belfast Research Portal is retained by the author(s) and / or other copyright owners and it is a condition of accessing these publications that users recognise and abide by the legal requirements associated with these rights.

Take down policy

The Research Portal is Queen's institutional repository that provides access to Queen's research output. Every effort has been made to ensure that content in the Research Portal does not infringe any person's rights, or applicable UK laws. If you discover content in the Research Portal that you believe breaches copyright or violates any law, please contact openaccess@qub.ac.uk. 
1 TITLE: Ultrawidefield fluorescein angiography as a biomarker for response to

2 switch in therapy in persistent diabetic macular edema

4 AUTHORS: Bobak Bahrami, MBBS, $\mathrm{PhD} *, \uparrow$ Thomas Hong, $\mathrm{PhD} *$ Tunde Peto,

$5 \mathrm{PhD}^{\wedge}, * *$ Andrew Chang, FRANZCO, $\mathrm{PhD}^{*}, \dagger$

6

$7 \quad$ *Sydney Institute of Vision Science, Sydney, New South Wales, AUSTRALIA

8 †Save Sight Institute, University of Sydney, Sydney, New South Wales,

9 AUSTRALIA.

$10 \wedge^{\wedge}$ NIHR Biomedical Research Centre at Moorfields Eye Hospital, NHS Foundation

11 Trust and UCL Institute of Ophthalmology, London, UK

$12 * *$ School of Medicine, Dentistry and Biomedical Sciences, Queen's University

13 Belfast, Northern Ireland, Belfast, UK

14

15 Dr Andrew Chang has acted as a consultant for Allergan, Bayer and Novartis. Dr

16 Tunde Peto has acted for a consultant for Novartis, Optos and Bayer.

17 Financial support was provided by Bayer Corporation Global. The sponsor had

18 no role in the design, conduct or analysis of this research. None of the authors

19 have any proprietary interest in any material or method presented.

20

21 CORRESPONDENCE:

22 Dr. Andrew Chang

23 Sydney Retina Clinic and Day Surgery

24 13/187 Macquarie Street

25 Sydney, New South Wales 2000, Australia

26 Telephone: +61292213755

27 Fax: +61292211637

28 Email: achang@sydneyretina.com.au 


\section{Purpose}

To explore the effect of peripheral ischemia identified on ultrawidefield fluorescein angiography (UWFA) as a biomarker of response to switch in therapy from bevacizumab to aflibercept in persistent diabetic macular edema (DME).

\section{Methods}

37 Prospective clinical trial of 38 eyes from 38 patients previously treated with bevacizumab and persistent DME. Patients subsequently received aflibercept per protocol and were followed up for 48 weeks. UWFA was obtained on all patients at baseline and 48 weeks. Images were graded and used to calculate an overall ischemic index (II) and macular ischemic index (MII). II was compared with visual and central macular thickness (CMT) outcomes. Paired and independent samples t-tests and Fisher's exact tests were used to assess change and associations.

\section{Results}

47 Patients with an II greater than or equal to $50 \%$ at baseline had a poorer baseline 48 visual acuity $(60.1 \pm 10.2$ vs. $70.7 \pm 9.0$ letters, $p=0.005)$ and a worse MII $(6.9 \pm$ 4925 vs. $56 \pm 52 \%$, p < 0.001 ). These patients gained significantly more vision at 48 50 weeks ( $8.3 \pm 9.3$ vs. $2.6 \pm 5.9$ letters, $p=0.03)$. At 48 weeks, there was no

51 significant difference in visual acuity of patients with an II greater or less than $5250 \%(68.4 \pm 6.0$ vs. $73.3 \pm 9.6$ letters, $\mathrm{p}=0.16)$. 


\section{Conclusion}

55 Patients with persistent DME treated with bevacizumab and worse II had poorer

56 baseline visual acuity, potentially due to worse macular ischemia. These patients

57 had greater visual gain with similar final visual outcomes of those without

58 marked peripheral ischemia subsequent to switching to aflibercept. 


\section{BACKGROUND}

Ocular imaging is a cornerstone of diagnosis and management of diabetic macular edema (DME). Historically, fluorescein angiography (FA) has played a pivotal role in qualifying vascular leakage and guiding therapy for DME. [1] In the past two decades, optical coherence tomography (OCT) has revolutionized diagnosis of DME, as well as led to the identification of prognostic biomarkers such as distribution of edema, disruption to the inner segment ellipsoid (ISe) band and external limiting membrane (ELM), and disorganization of the inner retinal layers (DRIL). [2-5]

More recently, ultrawidefield (UW) imaging enabled documentation of peripheral lesions, leading to more detailed description of disease severity and prognosis of progression. [6, 7] When combined with FA, ultrawidefield fluorescein angiography (UWFA) has been shown to identify 3.9 times more nonperfusion, 1.9 times more neovascularization, and 1.1 times more retinal pathology as compared with standard 7-fields photography. [8]

Peripheral ischemia may be quantified through the calculation of an ischemic index (II). [9] Such an index gives a ratio of non-perfused to perfused retina and has been shown to be associated with the prevalence of DME in a retrospective study of 122 eyes (OR 3.75, 95\%CI 1.26-11.13, p<0.02). [10] Furthermore, DME that is recalcitrant to macular photocoagulation was found to be associated with a worse II in a retrospective study of 148 eyes with persistent DME. [11] These patients also required a greater number of treatments with macular laser photocoagulation and had a lesser reduction in the CMT. 
85 It is unclear what prognostic information can be gained from UWFA for patients

86 with DME being treated with anti-VEGF drugs. Herein we report the prognostic

87 value of UWFA from a prospective clinical trial where patients with persistent

88 DME were switched from bevacizumab to aflibercept. 


\section{METHODS}

\section{Participants}

All patients gave informed consent to participate in this prospective, nonrandomized, open-label clinical trial. The study adhered to the Declaration of Helsinki and was registered on the Australian and New Zealand Clinical Trials Registry (ACTRN12614001307695).

Full inclusion and exclusion criteria for the patients enrolled in this trial have previously been reported. [12] Briefly, patients were aged 18 years or older and had DME with a central macular thickness greater than $300 \mu \mathrm{m}$ in the spectral domain optical coherence tomography (OCT; Spectralis, Heidelberg Engineering, Heidelberg, Germany), best corrected visual acuity (BCVA) between 34 and 85 Early Treatment of Diabetic Retinopathy Study (ETDRS) letters and at least 4 previous intravitreal injections of bevacizumab $(2.5 \mathrm{mg} / 0.1 \mathrm{~mL})$ in the 6 months prior to enrolment. Patients then received intravitreal aflibercept $(2.0 \mathrm{mg} / 0.1 \mathrm{~mL})$ in one eye only every four weeks for a total of five injections at which point the treatment interval was extended to injections every eight weeks for a total follow up of 48 weeks. BCVA and CMT assessments occurred at every four weeks with UWFA occurring at baseline and at 48 weeks.

\section{Image Acquisition}

UWFA images were acquired using the Optos 200TX (Optos Plc, Dunfermline, Scotland). An intravenous bolus of $5 \mathrm{~mL}$ of $10 \% \mathrm{w} / \mathrm{v}$ fluorescein was given and images were obtained in the transit phase (up to 45 seconds) arteriovenous 
113 phase (1 to 2 minutes) and during recirculation (up to 10 minutes). A single best

114 image from the arteriovenous phase of the study eye was selected for grading.

Calculation of ischemic index

117 The ischemic index was calculated using the concentric rings method previously 118 described. [13] Briefly, UWFA images for each patient at baseline and 48 weeks

119 were overlaid with the template of seven concentric rings (Figure 1) as supplied

120 in the supplement to the publication by Nicholson et al. [13] Using Image

121 software (NIH, Bethesda, Maryland), the template was resized and repositioned

122 for each image such that the innermost ring was equal in size to the optic disc

123 and the central point of the template was placed at the fovea. Each of these seven

124 rings was divided into 12 equal segments subtending an angle of 30 degrees at

125 the fovea. Each segment was graded as perfused, non-perfused or non-gradable

126 if more than half of the segment consisted of one of the three. Grading was

127 validated by an independent trained external grader (TP). Areas with scatter

128 laser were deemed not gradable and were excluded from the calculation of the

129 index.

131 The II was calculated from the grading by multiplying each segment by the total

132 disc area represented and then dividing non-perfused retina by the total

133 gradable area. An ischemic index of $50 \%$ or above was considered to be high as

134 previously described and further analyses were based on this definition. [14]

135 The macular ischemic index (MII) was calculated from the 12 sectors comprising

136 the innermost ring of the template. 
139 Images were graded for morphology of DME (intraretinal fluid and/or subretinal

140 fluid), presence or absence of disorganization of the inner retinal layers (DRIL)

$141>50 \%$, inner segment ellipsoid (ISe) band disruption, external limiting

142 membrane (ELM) disruption in a $1 \mathrm{~mm}$ area centered around the fovea as

143 previously described and reported. [2, 12, 15, 16]

145 Statistical Analysis

146 All statistical tests were performed and figures produced using IBM SPSS

147 software (version 22; SPSS Inc, Chicago, Illinois, USA). Patients were grouped by

148 baseline II greater than or less than or equal to $50 \%$. Data was confirmed to be

149 distributed normally using Shapiro-Wilk tests. Homogeneity of data was

150 confirmed using Levene's test for all independent samples' t-tests. Adjustment

151 was made to the analysis using the Welch-Satterthwaite method for data that

152 was not homogenous. Fisher's exact test was used to analyze categorical data

153 when sample sizes in groups were small. Pearson's correlation coefficient was

154 calculated for correlation analyses. For all analyses, a p-value of less than 0.05

155 was considered to be statistically significant. 


\section{RESULTS}

Of the 43 patients recruited, one withdrew consent after the baseline visit, one was withdrawn due to a retinal detachment in the study eye after the second injection, three did not have UWFA performed at baseline and six did not have UWFA performed at 48-weeks. The characteristics of the 38 patients with complete UWFA data at baseline included for analysis are summarized in Table 1.

BCVA improved by a mean \pm standard deviation of $4.0 \pm 7.2$ letters $(p=0.002) \underline{\text { to }}$

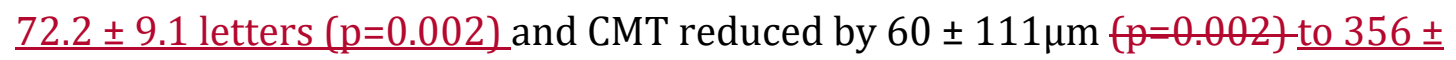
$109 \mu \mathrm{m}(\mathrm{p}=0.002)$ in the 38 patients with UWFA data at baseline over the 48week study period.

There was no significant change in mean II $(24.9 \pm 32.5 \%$ to $22.7 \pm 29.7 \%$, $\mathrm{p}=0.36)$ or MII $(8.1 \pm 23.5 \%$ to $7.9 \pm 19.7 \%, \mathrm{p}=0.88)$ from baseline to 48 -weeks. There was correlation between II and MII at baseline $(r=0.66, p<0.001)$ and at 48-weeks ( $\mathrm{r}=0.57, \mathrm{p}<0.001)$.

Patients with an II greater than $50 \%(n=9)$ at baseline had a poorer baseline visual acuity ( $60.1 \pm 10.2$ vs. $70.7 \pm 9.0$ letters, $p=0.005$; Figure $2 A)$ and a worse MII ( $6.9 \pm 25 \%$ vs. $56 \pm 52 \%, p<0.001)$ compared to patients with a lower II $(\leq 50 \%)$. These patients gained significantly more letters of vision at 48 weeks $(8.3 \pm 9.3$ vs. $2.6 \pm 5.9$ letters, $p=0.03)$. At 48 weeks, there was no significant difference in absolute visual acuity in patients with an II greater than $50 \%$ compared to those with an index less than or equal to $50 \%(68.4 \pm 6.0$ vs. $73.3 \pm$ 
18
18
18
18
18

186 9.6 letters, p=0.16; Figure 2B). There was no significant difference in baseline $(69.4 \pm 9.3$ vs. $63.0 \pm 13$ letters, $p=0.14)$ or final $(72.6 \pm 9.4$ vs. $70.3 \pm 7.9$ letters, $\mathrm{p}=0.18)$.

$\mathrm{p}=0.55)$ BCVA in patients with the absence or presence of macular ischemia, nor were the BCVA gains in these two groups different $(3.2 \pm 6.9$ vs. $7.3 \pm 8.1$ letters,

There was no difference in CMT at baseline or 48-weeks for patients with an II greater than $50 \%$ at baseline compared with those less than or equal to $50 \%$ ( $429 \pm 61 \mu \mathrm{m}$ vs. $412 \pm 101 \mu \mathrm{m}, \mathrm{p}=0.63$ and $395 \pm 112 \mu \mathrm{m}$ vs. $343 \pm 107 \mu \mathrm{m}$ $\mathrm{p}=0.22$, respectively; Figure 3). There was no difference in change in CMT for patients with an II greater than $50 \%$ ( $-34 \pm 73 \mu \mathrm{m}$ vs. $-68 \pm 120 \mu \mathrm{m}, \mathrm{p}=0.42)$.

There was no significant correlation between CMT at baseline $(r=0.18, p=0.29)$ or change in CMT at 48-weeks ( $\mathrm{r}=0.16, \mathrm{p}=0.33$ ) with the MII.

There was no significant correlation between baseline II and $\mathrm{HbA1c}(\mathrm{r}=0.16$, $\mathrm{p}=0.40)$, duration of diabetes $(\mathrm{r}=0.25, \mathrm{p}=0.13)$, or number of previous anti-VEGF injections for DME $(\mathrm{r}=-0.31, \mathrm{p}=0.06)$. There was no significant correlation between baseline MII and HbA1c $(r=0.01, p=0.96)$, duration of diabetes $(r=0.21$, $\mathrm{p}=0.20)$, or number of previous anti-VEGF injections for DME $(\mathrm{r}=-0.23, \mathrm{p}=0.17)$.

There was no correlation between II or MII and presence of subretinal fluid, disorganization of the inner retinal layers, external limiting membrane or inner segment ellipsoid band disruption (Table 2 data not shown). 


\section{DISCUSSION}

207 Among patients with persistent DME and significant prior treatment with 208 bevacizumab, a high baseline II greater than 50\% was associated with a poorer 209 baseline visual acuity. However, these patients had a similar final visual acuity to 210 those with a low baseline II when therapy was switched to aflibercept.

212 Visual acuity is dependent on the health of the macula, both in the available

213 blood supply as well as the integrity of the various cells involved in

214 phototransduction. In this study, visual acuity was not associated with a thicker

215 CMT but with worse macular ischemia. Recent studies utilizing OCT angiography

216 have identified a negative correlation between macular capillary density and

217 visual acuity. [17] OCT biomarkers such as ISe band and ELM disruption, DRIL

218 and presence of subretinal fluid are all associated with a poorer visual acuity. [2-

219 5] Whilst ischemia may be postulated to explain these structural abnormalities,

220 presence of these factors did not correlate with macular ischemia in this study.

222 There are several potential explanations for a greater gain in vision for the

223 patients with a higher baseline II. Firstly, the starting visual acuity was

224 significantly lower, meaning that there was more potential for vision gain.

225 Secondly, there may be a "ceiling effect", to the amount of vision that can be

226 gained in this cohort of patients with persistent DME. Finally, ischemia and

227 hypoxia are strongly implicated in the pathogenesis of DME. Areas of untreated

228 retinal non-perfusion may stimulate the production of mediators such as VEGF-A

229 and placental growth factor (PlGF) that contribute to the formation and

230 persistence of DME. Whilst there is no control group to compare to in this study, 
231 these factors may be more effectively inhibited by aflibercept leading to

232 improved outcomes in these patients. [18]

233

234 It has been hypothesized that scatter photocoagulation to areas of peripheral

235 ischemia may help in the management of DME. Complete resolution of macular

236 edema following panretinal photocoagulation was demonstrated in a case series

237 of 17 eyes with florid proliferative DR and DME. [19] Worsening of DME was

238 reduced over a period of six months in a clinical trial of 52 patients randomized

239 to a single dose of bevacizumab either with or without targeted

240 photocoagulation. [20] Reduced levels of VEGF in the eye following panretinal

241 photocoagulation (PRP) may be responsible for this effect. [21] However, PRP is

242 also known to exacerbate macular edema likely through transient increases in

243 inflammatory cytokines and VEGF. [22, 23]

245 Most recently, monotherapy with ranibizumab was shown to have similar

246 outcomes to combination therapy with ranibizumab and targeted laser

247 photocoagulation in a three year, randomized trial of 40 eyes from 29 patients

248 with DME and significant peripheral ischemia. [24] There were no differences in

249 treatment burden or visual or anatomical outcomes. The authors suggested

250 areas of non-perfusion may represent dead rather than stressed tissue and thus

251 do not contribute to increased production of factors driving DME. This is similar

252 to the outcomes presented in the RELATE study, where patients with branch and

253 central retinal vein occlusion who were randomized to intravitreal ranibizumab

254 therapy with targeted scatter laser had similar vision and anatomical outcomes

255 to those treated with ranibizumab monotherapy. [25] 
257 Contrary to Wessel et al, we did not find any correlation between diabetes

258 control and II, nor did we find a relationship between duration of diabetes and II.

259 [10] Furthermore, we did not confirm findings of other studies presenting data

260 suggesting a reversal of areas of non-perfusion with intravitreal injection of anti-

261 VEGF drugs or dexamethasone implant. [26, 27]

263 The strengths of this study are in the prospective and standardized nature of

264 data collection in a clinical trial setting. The trial participants received the per

265 protocol treatment during the study period and had retinal imaging performed

266 at standardized time points. The methodology for grading ischemia has been

267 previously validated.

269 There are inherent limitations in the data and analyses performed due to lack of

270 a control arm as well as a relatively small sample size from a single center.

$271 \quad$ Patients included had heterogeneous prior treatments including macular and

272 panretinal photocoagulation. Furthermore, correction for peripheral distortion

273 and introducing validated, reliable computer based segmentation for the

274 calculation of peripheral ischemia may yield more accurate results in the future.

$275[28,29]$

277 The exploratory analyses from this study demonstrate that significant peripheral

278 retinal ischemia may correlate with poorer visual acuity and a greater capacity

279 for vision improvement in patients with persistent DME switched to aflibercept.

280 Additionally, there appears to be no clear association between degree of 
281 peripheral ischemia and severity of macular edema, suggesting that other factors 282 may be involved in macular thickening in DME. Future directions for these

283 findings are to assess the effect of peripheral ischemia as a biomarker of

284 treatment response to anti-VEGF drugs in treatment naïve eyes as well as those

285 treated with other modalities such as corticosteroids that target different 286 pathological pathways. 
1. Early Treatment Diabetic Retinopathy Study research group (1985)

6. Silva PS, Cavallerano JD, Haddad NM, Kwak H, Dyer KH, Omar AF, Shikari Photocoagulation for diabetic macular edema. Early Treatment Diabetic Retinopathy Study report number 1. Archives of ophthalmology 103: 1796-1806

2. Maheshwary AS, Oster SF, Yuson RM, Cheng L, Mojana F, Freeman WR (2010) The association between percent disruption of the photoreceptor inner segment-outer segment junction and visual acuity in diabetic macular edema. American journal of ophthalmology 150: 63-67 e61 DOI 10.1016/j.ajo.2010.01.039

3. Murakami T, Nishijima K, Sakamoto A, Ota M, Horii T, Yoshimura N (2011) Association of pathomorphology, photoreceptor status, and retinal thickness with visual acuity in diabetic retinopathy. American journal of ophthalmology 151: 310-317 DOI 10.1016/j.ajo.2010.08.022

4. Otani T, Yamaguchi Y, Kishi S (2010) Correlation between visual acuity and foveal microstructural changes in diabetic macular edema. Retina 30: 774-780 DOI 10.1097/IAE.0b013e3181c2e0d6

5. Sun JK, Lin MM, Lammer J, Prager S, Sarangi R, Silva PS, Aiello LP (2014) Disorganization of the retinal inner layers as a predictor of visual acuity in eyes with center-involved diabetic macular edema. JAMA ophthalmology 132: 1309-1316 DOI 10.1001/jamaophthalmol.2014.2350 H, Aiello LM, Sun JK, Aiello LP (2015) Peripheral Lesions Identified on Ultrawide Field Imaging Predict Increased Risk of Diabetic Retinopathy Progression over 4 Years. Ophthalmology 122: 949-956 DOI 10.1016/j.ophtha.2015.01.008

7. Silva PS, El-Rami H, Barham R, Gupta A, Fleming A, van Hemert J, Cavallerano JD, Sun JK, Aiello LP (2017) Hemorrhage and/or Microaneurysm Severity and Count in Ultrawide Field Images and Early Treatment Diabetic Retinopathy Study Photography. Ophthalmology 124: 970-976 DOI 10.1016/j.ophtha.2017.02.012

8. Wessel MM, Aaker GD, Parlitsis G, Cho M, D'Amico DJ, Kiss S (2012) Ultrawide-field angiography improves the detection and classification of diabetic retinopathy. Retina 32: 785-791 DOI 10.1097/IAE.0b013e3182278b64

9. Tsui I, Kaines A, Havunjian MA, Hubschman S, Heilweil G, Prasad PS, Oliver SC, Yu F, Bitrian E, Hubschman JP, Friberg T, Schwartz SD (2011) Ischemic index and neovascularization in central retinal vein occlusion. Retina 31: 105-110 DOI 10.1097/IAE.0b013e3181e36c6d

10. Wessel MM, Nair N, Aaker GD, Ehrlich JR, D'Amico DJ, Kiss S (2012) Peripheral retinal ischaemia, as evaluated by ultra-widefield fluorescein angiography, is associated with diabetic macular oedema. The British journal of ophthalmology 96: 694-698 DOI 10.1136/bjophthalmol-2011300774

11. Patel RD, Messner LV, Teitelbaum B, Michel KA, Hariprasad SM (2013) Characterization of ischemic index using ultra-widefield fluorescein 
angiography in patients with focal and diffuse recalcitrant diabetic macular edema. American journal of ophthalmology 155: 1038-1044 e1032 DOI 10.1016/j.ajo.2013.01.007

12. Bahrami B, Hong T, Zhu M, Schlub TE, Chang A (2017) Switching therapy from bevacizumab to aflibercept for the management of persistent diabetic macular edema. Graefe's archive for clinical and experimental ophthalmology = Albrecht von Graefes Archiv fur klinische und experimentelle Ophthalmologie 255: 1133-1140 DOI 10.1007/s00417017-3624-y

13. Nicholson L, Vazquez-Alfageme C, Ramu J, Triantafyllopoulou I, Patrao NV, Muwas M, Islam F, Hykin PG, Sivaprasad S (2015) Validation of Concentric Rings Method as a Topographic Measure of Retinal Nonperfusion in UltraWidefield Fluorescein Angiography. American journal of ophthalmology 160: 1217-1225 e1212 DOI 10.1016/j.ajo.2015.09.003

14. Sim DA, Keane PA, Rajendram R, Karampelas M, Selvam S, Powner MB, Fruttiger M, Tufail A, Egan CA (2014) Patterns of peripheral retinal and central macula ischemia in diabetic retinopathy as evaluated by ultrawidefield fluorescein angiography. American journal of ophthalmology 158: 144-153 e141 DOI 10.1016/j.ajo.2014.03.009

15. Sun JK, Radwan SH, Soliman AZ, Lammer J, Lin MM, Prager SG, Silva PS, Aiello LB, Aiello LP (2015) Neural Retinal Disorganization as a Robust Marker of Visual Acuity in Current and Resolved Diabetic Macular Edema. Diabetes 64: 2560-2570 DOI 10.2337/db14-0782

16. Bahrami B, Hong T, Schlub TE, Chang AA (2019) AFLIBERCEPT FOR PERSISTENT DIABETIC MACULAR EDEMA: Forty-Eight-Week Outcomes. Retina 39: 61-68 DOI 10.1097/IAE.0000000000002253

17. Samara WA, Shahlaee A, Adam MK, Khan MA, Chiang A, Maguire JI, Hsu J, Ho AC (2017) Quantification of Diabetic Macular Ischemia Using Optical Coherence Tomography Angiography and Its Relationship with Visual Acuity. Ophthalmology 124: 235-244 DOI 10.1016/j.ophtha.2016.10.008

18. Papadopoulos N, Martin J, Ruan Q, Rafique A, Rosconi MP, Shi E, Pyles EA, Yancopoulos GD, Stahl N, Wiegand SJ (2012) Binding and neutralization of vascular endothelial growth factor (VEGF) and related ligands by VEGF Trap, ranibizumab and bevacizumab. Angiogenesis 15: 171-185 DOI 10.1007/s10456-011-9249-6

19. Gaucher D, Fortunato P, LeCleire-Collet A, Bourcier T, Speeg-Schatz C, Tadayoni R, Massin P (2009) Spontaneous resolution of macular edema after panretinal photocoagulation in florid proliferative diabetic retinopathy. Retina 29: 1282-1288 DOI 10.1097/IAE.0b013e3181a91e9f

20. Takamura Y, Tomomatsu T, Matsumura T, Arimura S, Gozawa M, Takihara Y, Inatani M (2014) The effect of photocoagulation in ischemic areas to prevent recurrence of diabetic macular edema after intravitreal bevacizumab injection. Investigative ophthalmology \& visual science 55: 4741-4746 DOI 10.1167/iovs.14-14682

21. Aiello LP, Avery RL, Arrigg PG, Keyt BA, Jampel HD, Shah ST, Pasquale LR, Thieme H, Iwamoto MA, Park JE, et al. (1994) Vascular endothelial growth factor in ocular fluid of patients with diabetic retinopathy and other retinal disorders. The New England journal of medicine 331: 1480-1487 DOI 10.1056/NEJM199412013312203 
22. McDonald HR, Schatz H (1985) Macular edema following panretinal photocoagulation. Retina 5: 5-10

23. Ito A, Hirano Y, Nozaki M, Ashikari M, Sugitani K, Ogura Y (2015) Short pulse laser induces less inflammatory cytokines in the murine retina after laser photocoagulation. Ophthalmic research 53: 65-73 DOI 10.1159/000366520

24. Brown DM, Ou WC, Wong TP, Kim RY, Croft DE, Wykoff CC, Group DS (2018) Targeted Retinal Photocoagulation for Diabetic Macular Edema with Peripheral Retinal Nonperfusion: Three-Year Randomized DAVE Trial. Ophthalmology DOI 10.1016/j.ophtha.2017.11.026

25. Campochiaro PA, Hafiz G, Mir TA, Scott AW, Solomon S, Zimmer-Galler I, Sodhi A, Duh E, Ying H, Wenick A, Shah SM, Do DV, Nguyen QD, Kherani S, Sophie R (2015) Scatter Photocoagulation Does Not Reduce Macular Edema or Treatment Burden in Patients with Retinal Vein Occlusion: The RELATE Trial. Ophthalmology 122: 1426-1437 DOI 10.1016/j.ophtha.2015.04.006

26. Levin AM, Rusu I, Orlin A, Gupta MP, Coombs P, D'Amico DJ, Kiss S (2017) Retinal reperfusion in diabetic retinopathy following treatment with antiVEGF intravitreal injections. Clinical ophthalmology 11: 193-200 DOI 10.2147/OPTH.S118807

27. Querques L, Parravano M, Sacconi R, Rabiolo A, Bandello F, Querques G (2017) Ischemic index changes in diabetic retinopathy after intravitreal dexamethasone implant using ultra-widefield fluorescein angiography: a pilot study. Acta diabetologica 54: 769-773 DOI 10.1007/s00592-0171010-1

28. Tanchon C, Srivastava SK, Ehlers JP (2015) Automated Quantitative Analysis of Leakage and Ischemia for Ultra-widefield Angiography in Retinal Vascular Disease. Investigative ophthalmology \& visual science 56: 3067-3067

29. Tan CS, Chew MC, van Hemert J, Singer MA, Bell D, Sadda SR (2016) Measuring the precise area of peripheral retinal non-perfusion using ultra-widefield imaging and its correlation with the ischaemic index. The British journal of ophthalmology 100: 235-239 DOI 10.1136/bjophthalmol-2015-306652 
TITLES AND LEGENDS TO FIGURES

420

421 Figure 1: Ultra-widefield fluorescein angiography with concentric rings overlay

422

423 Figure 2. Boxplot showing baseline (A) and 48-week (B) visual acuities grouped

424 by baseline ischemic index

425

426 Figure 3. Boxplot showing baseline (A) and 48-week (B) central macular

427 thickness grouped by baseline ischemic index 
Table 1. Baseline characteristics of patients included in analysis

\begin{tabular}{|l|l|}
\hline Characteristic & Data \\
\hline Number of patients & 38 \\
\hline Age (years), mean \pm SD & $62.6 \pm 9.7$ \\
\hline Male, $\mathrm{n}(\%)$ & $26(68)$ \\
\hline Right eyes, $\mathrm{n}(\%)$ & $18(47)$ \\
\hline Duration of diabetes (years), mean \pm SD & $17.5 \pm 11.1$ \\
\hline HbA1c (\%), mean \pm SD & $7.9 \pm 1.7$ \\
\hline Duration of anti-VEGF treatment (months), mean \pm SD & $25.0 \pm 22.2$ \\
\hline Total number of anti-VEGF injections, mean \pm SD & $16.4 \pm 11.2$ \\
\hline Prior treatments in study eye & \\
Focal/grid macular photocoagulation, $\mathrm{n}(\%)$ & $15(39.5)$ \\
Panretinal photocoagulation, n (\%) & $15(39.5)$ \\
Vitrectomy, n (\%) & $5(13.1)$ \\
\hline Baseline BCVA (letter score), mean \pm SD & $68.2 \pm 10.2$ \\
\hline Baseline CMT (microns), mean \pm SD & $416 \pm 93$ \\
\hline
\end{tabular}

$\mathrm{SD}=$ standard deviation, $\mathrm{VEGF}=$ vascular endothelial growth factor, $\mathrm{BCVA}=$ best corrected visual acuity, $\mathrm{CMT}=$ central macular thickness 
Table 2. Correlation of optical coherence tomography parameters with baseline ischemic index and macular ischemic index

\begin{tabular}{|l|l|l|l|l|}
\hline Characteristic & $\begin{array}{l}\text { External } \\
\text { limiting } \\
\text { membrane } \\
\text { disruption }\end{array}$ & $\begin{array}{l}\text { Presence } \\
\text { of } \\
\text { subretinal } \\
\text { fluid }\end{array}$ & $\begin{array}{l}\text { Presence of } \\
\text { inner } \\
\text { segment } \\
\text { ellipsoid } \\
\text { band } \\
\text { disruption }\end{array}$ & $\begin{array}{l}\text { Disorganization } \\
\text { of the retinal } \\
\text { inner layers } \\
\mathbf{5} \mathbf{5 0 \%}\end{array}$ \\
\hline $\begin{array}{l}\text { Baseline } \\
\text { Inchemic }\end{array}$ & $\mathrm{r}=0.24, \mathrm{p}=0.14$ & $\begin{array}{l}\mathrm{r}=-0.07, \\
\mathrm{p}=0.66\end{array}$ & $\begin{array}{l}\mathrm{r}=0.14, \\
\mathrm{p}=0.42\end{array}$ & $\mathrm{r}=0.08, \mathrm{p}=0.65$ \\
\hline $\begin{array}{l}\text { Baseline } \\
\text { Macular } \\
\text { Ischemic } \\
\text { Index }\end{array}$ & $\mathrm{r}=0.35, \mathrm{p}=0.06$ & $\begin{array}{l}\mathrm{r}=-0.14, \\
\mathrm{p}=0.42\end{array}$ & $\begin{array}{l}\mathrm{r}=0.17, \\
\mathrm{p}=0.30\end{array}$ & $\mathrm{r}=0.18, \mathrm{p}=0.28$ \\
\hline
\end{tabular}



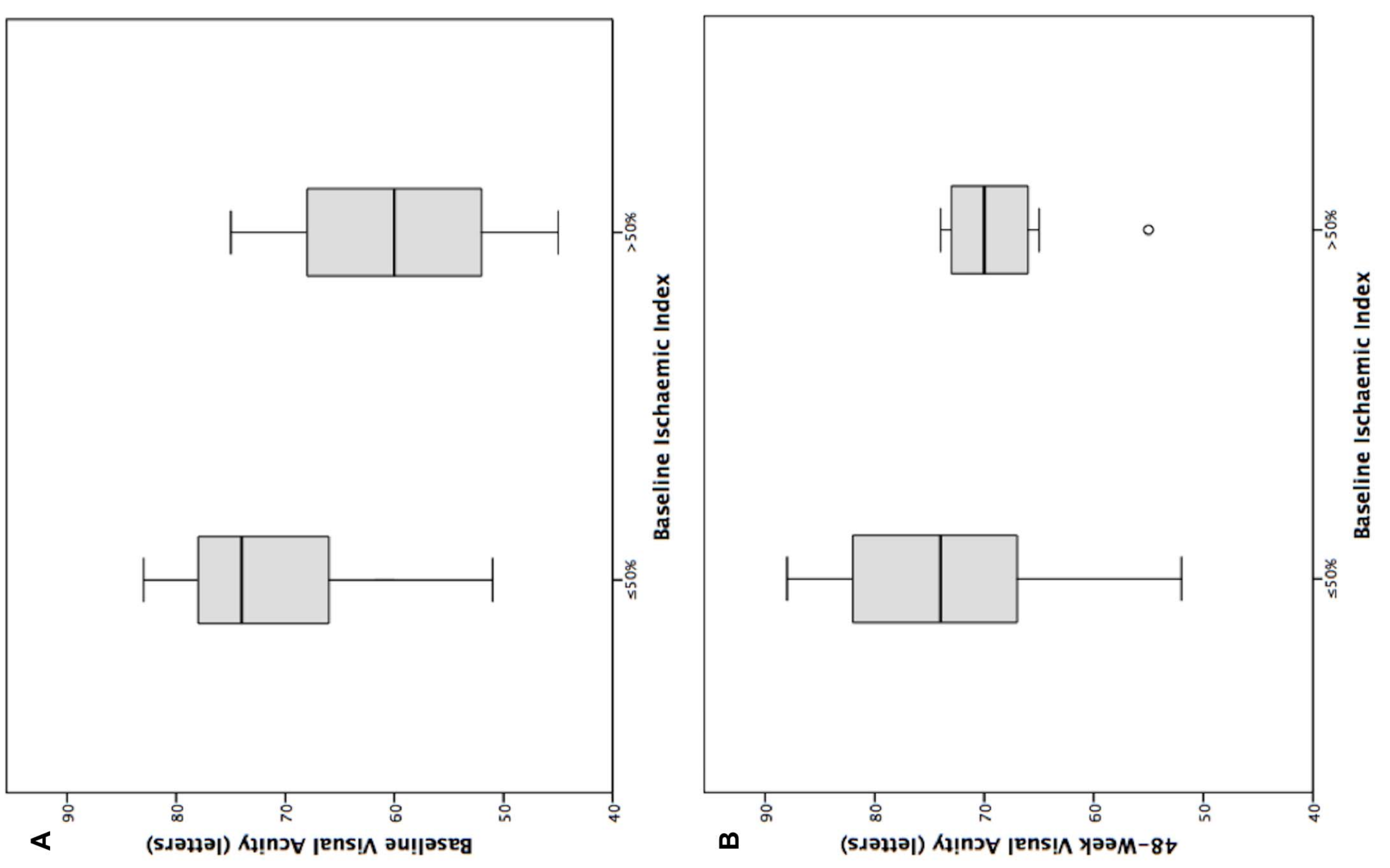


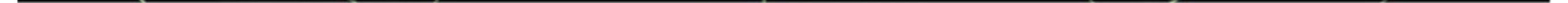



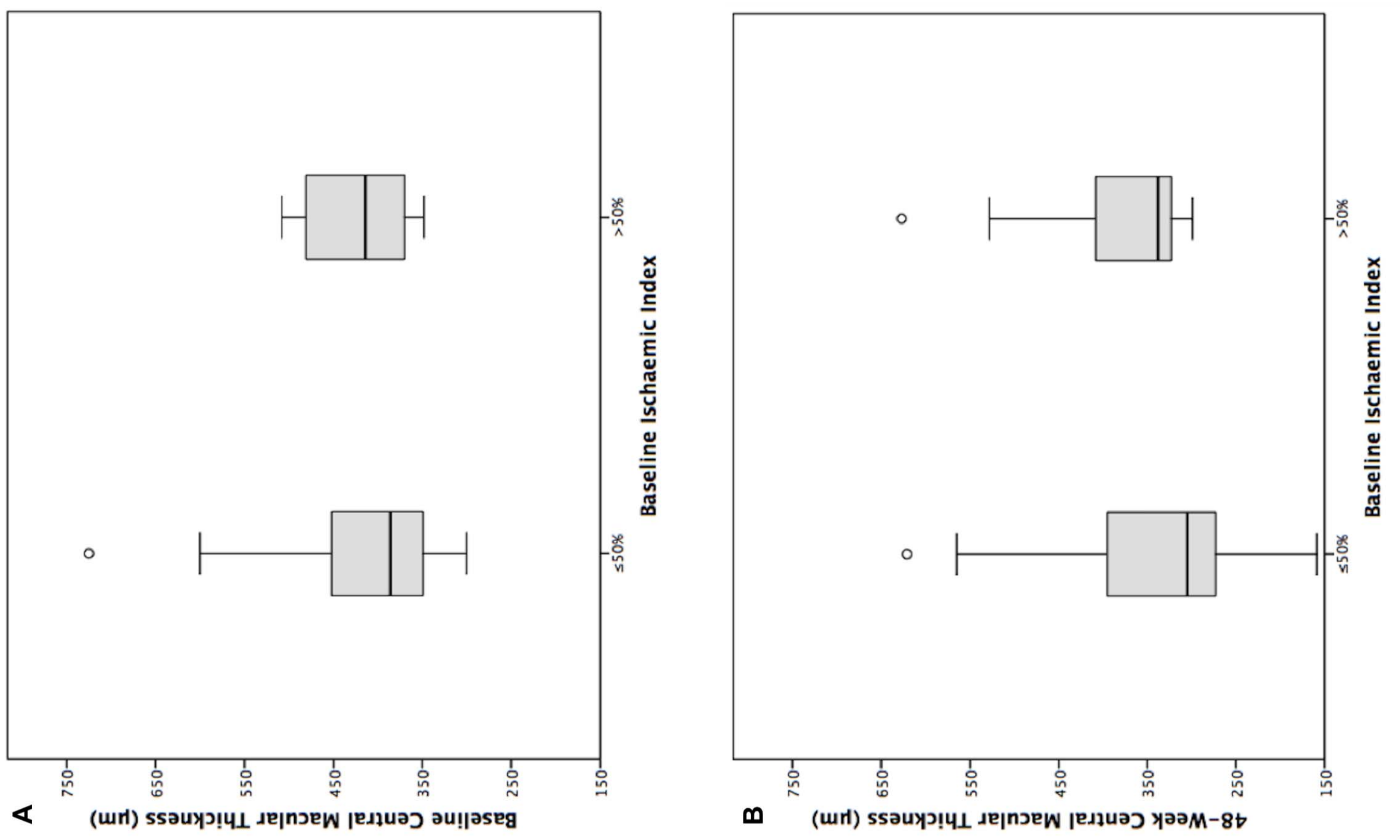